\title{
Juventude e trauma geracional: como os jovens brasileiros respondem à pandemia e à infodemia da Covid-19
}

\author{
Youth and generational trauma: how Brazilian young \\ adults' respond to the pandemic and the infodemic of the \\ Covid-19
}

\author{
Carla Baiense Felix ${ }^{a}$ (i) \\ Victor Nascimento Rocha a (D) \\ Patrícia Fernandes Viana Franco Castro a (D) \\ Larissa de Morais Ribeiro Mendes a (D) \\ Helen Pinto de Britto Fontes ${ }^{b}$ (D)
}

\begin{abstract}
RESUMO: A partir da compreensão da pandemia de Covid-19 como trauma global, investigamos como jovens das cinco regiões brasileiras lidam com a crise sanitária e suas consequências, a partir de suas interações com o noticiário. Em um ambiente marcado por perdas materiais e simbólicas, e atravessado pelo excesso de informações e desinformação, buscamos entender de que maneira nossos informantes reagem à exposição midiática ao evento traumático e que sentidos produzem para o que consideramos um trauma geracional (Edmunds, Turner, 2005). Para isto, realizamos uma revisão bibliográfica sobre mídia e trauma, letramento midiático e infodemia, e apresentamos os resultados de uma pesquisa online, conduzida nos dois últimos meses de 2020, com a participação de 855 pessoas, entre 15 e 29 anos.
\end{abstract}

Palavras-chave: Juventude; Noticiário; Covid-19; Infodemia; Trauma.

ABSTRACT: Apprehending the Covid-19 pandemic as a global trauma, we investigate how young people from the five Brazilian regions deal with the health crisis and its consequences based on their interactions with the news. In an environment marked by material and symbolic loses and crossed by an excess of information and misinformation, we seek to understand how our informants react to media exposure to the traumatic event and the meanings they produce for what we consider a generational trauma (Edmunds, Turner, 2005). For this purpose, we carried out a literature review on media and trauma, media literacy, and infodemic, and present the results of an online survey conducted in the last two months of 2020 with 855 people between 15 and 29 years old.

Keywords: Youth; News; Covid-19; Infodemic; Trauma.

a Programa de Pós-Graduação em Mídia e Cotidiano, Universidade Federal Fluminense, Niterói, RJ, Brasil.

b Departamento de Comunicação Social, Universidade Federal Fluminense, Niterói, RJ, Brasil.

*Correspondência para/Correspondence to: Carla Baiense Felix. E-mail: carlabaienses@yahoo.com.br.

Recebido em/Received: 15/04/2021; Aprovado em/Approved: 17/06/2021.

Artigo publicado em acesso aberto sob licença CC BY 4.0 Internacional $($ (i) 


\section{INTRODUÇÃO}

Em seu estudo sobre juventude e mudança social, Edmunds e Turner (2005) consideram que as gerações políticas podem ser identificadas em termos de trauma histórico ou cultural. Partindo do texto inaugural de Mannheim (1952), os autores buscaram identificar em que circunstâncias as juventudes tornaram-se politicamente ativas, ao longo do século XX, e discutiram o papel da memória coletiva (Halbwachs 2006) de traumas nesse processo. Eles argumentam que essa memória pode vir diretamente da experiência, mas é também interpretada, traduzida e organizada através da mídia. Em outras palavras, essas experiências traumáticas tiveram, necessariamente, uma dimensão midiática.

Com o advento dos grandes sistemas de comunicação em rede, essas memórias também puderam ser compartilhadas em escala mundial. Portanto, embora tenham um aspecto objetivo, em termos de localização temporal, as juventudes passaram a se caracterizar também por uma experiência marcada pelo trauma histórico ou cultural global.

Ao longo de 2020, pudemos observar como um evento traumático global, a pandemia de SARS-Covid-19, é construído em termos midiáticos, formando uma memória coletiva geracional. Neste sentido, as respostas dessa geração à emergência sanitária dependem, em grande parte, de como a mídia conforma essa experiência. O papel de tais narrativas se torna ainda mais importante num contexto marcado pela desinformação, produzida de maneira intencional, para causar confusão e dano numa escala mundial.

A reação da imprensa profissional à proliferação de informações falsas ou fora de contexto, "tão nocivas quanto o vírus" (Ghebreyesus 2020), tem sido um incremento do noticiário sobre o tema Covid-19 (Trentin 2020; Barcelos 2020; Freitas, Baptista 2020; Cajazeira et. al 2020). Mas a impossibilidade ou incapacidade dos cidadãos de lidarem com esse aumento do fluxo informacional, que a OMS caracteriza como uma infodemia, produz também insegurança e ansiedade (Felix, Fernandes 2018).

Neste sentido, compreendemos que, para além das implicações e desafios vividos cotidianamente durante a pandemia, pessoas em todo o mundo foram expostas uma segunda vez à realidade traumática, agora através das mídias. No Brasil, mesmo que milhões de cidadãos tenham vivenciado a morte e o adoecimento de amigos e parentes ou experimentado outras perdas materiais e subjetivas, é através do noticiário que tomam contato com o trauma de mais 482 mil óbitos em 15 meses (Painel Coronavírus 2021).

Em vista disso, e entendendo que a experiência midiática é parte importante do cotidiano das juventudes brasileiras, sobretudo aquelas que vivem nos grandes centros urbanos conectados, procuramos compreender como o noticiário contribui para a percepção dos jovens sobre a pandemia, entendida como um trauma global 
(Edmunds, Turner 2005). Para tal, realizamos um survey online, entre os meses de novembro e dezembro de 2020, compartilhado a partir das redes sociais dos pesquisadores e pesquisadoras do grupo Mídias, Redes e Jovens ${ }^{1}$, da Universidade Federal Fluminense. A pesquisa Juventude e mídia em tempos de pandemia contou com a participação de 855 jovens das cinco regiões brasileiras, que responderam o questionário de 30 perguntas através da ferramenta Google Forms.

Acreditamos que os dados coletados precisam ser analisados dentro do contexto experimentado pelas juventudes brasileiras no último ano. Neste sentido, é necessário compreender como se deu essa experiência juvenil em termos concretos, considerando, ainda, que não há uma única juventude, mas diferentes formas de vivenciar a condição juvenil (Dayrrel 2007).

Em termos estatísticos, o Estatuto da Juventude (Brasil 2013) considera jovens os sujeitos de 15 a 29 anos, o equivalente a 47,3 milhões de pessoas no Brasil (IBGE 2019). Ao longo de 2020, o Ministério da Saúde registrou 27 mil internações de mulheres e 24 mil internações de homens, entre 20 e 29 anos, por Síndrome Respiratória Aguda Grave (Coronavírus, 2021), incluindo infecções por Covid. Dos 6 aos 19 anos, foram mais de 16 mil meninas e 15 mil meninos internados, evidenciando o quadro de adoecimento dessa população, a despeito da ideia do senso comum, reforçada por pronunciamentos do presidente Jair Bolsonaro, de que a doença atinge apenas idosos e portadores de doenças pré-existentes.

Para além disso, a estratégia de fechamento das escolas, medida necessária para manter o isolamento e controlar a disseminação da Covid-19, também trouxe impactos importantes sobre esse público. Em todo o mundo 1,5 bilhão de estudantes deixaram de frequentar as instituições escolares, segundo a Unesco. No Brasil, isso significou não apenas prejuízos sobre o aprendizado, mas também trouxe perdas em termos de saúde física e mental, com a suspensão dos programas de segurança alimentar, mantidos pelas redes públicas de educação, o aumento da violência doméstica, a gravidez e os casamentos precoces (Reflexões 2020).

Outro retrato desse momento é revelado pela pesquisa Juventudes e Pandemia do Coronavírus (2020), realizada pelo Conselho Nacional de Juventude em parceria com a Fundação Roberto Marinho e outras instituições. Os dados indicam que $41 \%$ dos jovens entrevistados sofreram com redução ou perda total em sua renda pessoal devido à pandemia. No que tange à saúde mental, os jovens apontaram a ansiedade, o tédio e

\footnotetext{
${ }^{1}$ O grupo de pesquisa "Mídias, redes e jovens: usos e apropriações em contextos digitais", certificado pelo CNPq em 2014, investiga a relação entre mídia e juventude no Brasil, em um cenário de intensa midiatização e assimetrias sociais. Acreditando que a imbricação de mídias no cotidiano não pode ser reduzida a um fenômeno tecnológico ou mercadológico, busca compreendê-la em um contexto mais amplo de transformação sociocultural, fortemente manifestada entre a parcela jovem da população. Com base em Estudos Culturais latino-americanos e pesquisas sobre letramento midiático europeias, propõe pesquisas empíricas no mapeando de manifestações desta mudança, partindo dos usos e apropriações midiáticas da juventude. Além dos cinco autores, participaram desta pesquisa Luiza Gould, Carla Ramalho, Luciana Costa, Ana Paula Alencar e Marcella Tovar.
} 
a impaciência como os sentimentos mais presentes durante o isolamento social. Além desses, o medo também foi apresentado como sentimento significativo, principalmente quando relacionado ao receio de perder algum familiar, com $75 \%$ das respostas.

Um estudo da Fiocruz realizado durante o período mostra que $48,7 \%$ dos adolescentes brasileiros apresentam um quadro frequente de mau humor, nervosismo e preocupação em decorrência da pandemia. As meninas são as mais afetadas: no recorte por gênero, $61,6 \%$ delas enfrentam essas dificuldades, percepção reiterada pelo levantamento do Instituto Plano de Menina (Pandemia muda rotina, 2021).

Outros levantamentos realizados ao longo de 2020 apontam também para uma relação entre maior acesso às notícias sobre a pandemia e a intensificação dos vários tipos de sofrimento vividos no período. A pesquisa "COVID-19 e os impactos na saúde mental: uma amostra do Rio Grande do Sul” (Duarte et al 2020), realizada por professores do Instituto de Psicologia da Universidade Federal do Rio Grande do Sul, por exemplo, indicou que ter renda diminuída no período, fazer parte do grupo de risco e estar mais exposto a informações sobre mortos e infectados são fatores que provocaram maior prejuízo na saúde mental no período da pandemia.

E, já que a experiência pandêmica passa por sua construção midiática, as narrativas noticiosas também produzem sentido contra o pano de fundo da vida cotidiana. Compreendendo que ambas não se confundem, mas que tampouco podem ser desvinculadas, buscamos compreender as respostas que as juventudes dão a essa realidade traumática a partir de suas interações com o noticiário. Para isto, discutiremos aspectos ligados a infodemia, trauma e letramento midiático, e apresentaremos alguns dos resultados da pesquisa Juventude e mídia em tempos de pandemia.

\section{Um olhar sobre a infodemia}

Em julho de 2019, o Instituto Datafolha publicou uma pesquisa realizada com 2.086 entrevistados de 103 cidades brasileiras, a partir da qual projetava que $7 \%$ da população brasileira, ou 11 milhões de pessoas, julgariam que o planeta possui um formato diferente do que é atestado cientificamente (Moreira, 2019). Para alguns deles, o terraplanismo é uma certeza; para outros, uma ideia plausível, já que o grupo específico do qual fazem parte reafirma essa crença. Em ambos os casos, o saber científico é posto em xeque².

\footnotetext{
${ }^{2}$ A teoria negacionista que baseia a crença do terraplanismo não é nova. Em 1956 o inglês Samuel Rowbotham fundou a Sociedade da Terra Plana baseado em algumas leituras literais da Bíblia. A crença abriu novo espaço no imaginário social durante os últimos anos, aproveitando conexões formadas através das redes sociais. O movimento ganhou tanta força no Brasil que, em 2019, o país sediou a primeira convenção do gênero, a Flat Con, que, segundo os organizadores, contou com 400 participantes pagantes
} 
Nesse mesmo sentido, teorias da conspiração ganham força ao afirmarem que certas doenças como a poliomielite, por exemplo, não existem, e que as vacinas fazem parte de um complô mundial. Esse é o fenômeno que termos como "pós-verdade" e "autoverdade" buscam explicar. Em tal contexto, pensar sobre a verdade compartilhada é tentar compreender o instável.

Os exemplos citados são indícios de um movimento que se expande. Podemos mencionar alguns casos ainda mais atuais e talvez mais perigosos: a crença na Cloroquina como um medicamento eficaz no tratamento da Covid-19, a criação do vírus em laboratório pelo governo chinês, a alteração de estatísticas para elevar o número oficial de mortes causadas pela doença e até a inexistência do vírus. Tal qual acontece com o saber científico, o tipo de conhecimento produzido, adaptado e compartilhado pelo jornalismo é contestado ou descaracterizado diante das crenças.

Ainda em 2002, o pesquisador Gunther Eysenbach (2020) cunhou os termos Infodemiologia (infodemiology), Infodemia (Infodemic) e Infovigilância (infoveillance) para designar o fenômeno da avalanche de desinformação na área de saúde em um artigo para o American Journal of Medicine. Ele definiu a "infodemiologia" como uma nova disciplina e metodologia de pesquisa emergente que busca compreender como são determinadas e distribuídas as informações e desinformações na área da saúde.

A partir dos estudos de Eysenbach, a Organização das Nações Unidas para a Educação, a Ciência e a Cultura (Unesco) usou o termo desinfodemia em 2020 para tratar da larga crise de desinformação que corrompe conteúdos básicos sobre a Covid-19 e que se espalha de forma maciça. Para a organização, as falsas informações sobre a doença são mais tóxicas e letais do que quaisquer outras. Essa constatação figura em uma cartilha criada pela instituição para conscientizar a sociedade: Desinfodemia: decifrando a desinformação sobre Covid-19 (Posetti, Bontcheva 2020).

Para lutar contra essa crise de desinformação, Eysenbach propõe a atuação em quatro pilares: a tradução facilitada e precisa do conhecimento em linguagens que atinjam os diferentes públicos; refinamento do conhecimento, com filtragem e checagem dos fatos; o desenvolvimento de um letramento para o conhecimento eletrônico/midiático da saúde (eHealth Literacy); e o monitoramento e vigilância contínua da infodemia e da evolução dos padrões de dados na internet.

Num contexto em que as opiniões e vontades pessoais passam a ter mais valor do que o conhecimento produzido e compartilhado através da academia e da imprensa, entendemos que as instituições mediadoras se enfraquecem na organização social. Isso abriria espaços para que grupos negacionistas se formem e, sobretudo a partir dos afetos desmedidos (Maffesoli, 1998), alcancem extremos. Também nesse sentido, as pesquisas sobre o contato das mídias informativas com seu público se provam fundamentais.

(Garcia 2019). 
Embora se reconheça a necessidade e importância do jornalismo profissional para combater o cenário de desinformação, a quantidade e a qualidade da informação produzida pela imprensa contribui, em certa medida, para gerar instabilidade e medo. Como dissemos, estes sentimentos não estão desconectados da própria realidade pandêmica. Mas o fato de o presidente da OMS, Thedros Adhanom, convocar governos, empresas e organizações de mídia para trabalharem juntos, e produzirem níveis de alarme apropriados, sem promover a histeria (Ghebreyesus 2020), indica uma preocupação com o tom e a ênfase da cobertura noticiosa sobre o evento.

\section{Mídia e trauma}

Em termos psicanalíticos, o trauma refere-se a um evento violento ao qual uma pessoa não é capaz de responder adequadamente, porque excede os níveis de excitação externa que seu aparato psíquico é capaz de tolerar (Kilomba 2020). Compreendemos que a intensidade da experiência pandêmica, assim como a excessiva exposição secundária ao evento traumático, através da mídia, são potencialmente produtoras de trauma.

Pesquisas internacionais buscaram aprofundar o conhecimento sobre a relação entre a emergência sanitária e o aumento da procura por notícias, ligadas ou não ao evento. Analisando a variação de dados sobre audiência do American Trends Panel, produzido pelo Pew Research Center, Casero-Ripollés observou que o surto de Covid-19 causou um impacto significativo no acesso ao noticiário entre a população estadunidense com mais de 18 anos. A pesquisa mapeou o consumo noticioso de 2.014 pessoas em relação a assuntos públicos relevantes (2020, p. 113).

Entre os jovens de 18 a 29 anos, esse aumento chegou a 47 pontos em relação ao período anterior ao estado de emergência. Em assuntos políticos, 39\% dos jovens consumiam notícias regularmente, número que chegou a $86 \%$ após a declaração da pandemia pela OMS.

Dados europeus corroboram essa tendência. Os canais de televisão públicos registraram um aumento de $20 \%$ na audiência nos telejornais noturnos entre os jovens. "Na Espanha, o consumo televisivo nesta faixa etária diante da emergência sanitária foi de 59,6\% e o consumo da imprensa digital foi de 72\%" (Casero-Ripollés op. cit, p.117).

Em um estudo conduzido em abril de 2020, através das redes sociais, na Rússia, Nekliudov et al (2020) associaram o acréscimo do consumo de notícias sobre Covid-19 a um aumento nos níveis de ansiedade da população. Os dados, no entanto, também estão correlacionados à perda de emprego e à queda de confiança nas agências governamentais.

Estudos anteriores também investigaram a relação entre mídia e outros eventos traumáticos. Bodas et al (2015) analisaram a relação de telespectadores judeus em 
Israel com o noticiário durante uma operação militar na região de Gaza. Os dados apontaram para uma relação entre o aumento da frequência de consumo noticioso televisivo de conteúdo traumático e sintomas de ansiedade, tais como medo incontrolável, agitação, distúrbios do sono e inquietações emocionais. O estudo indica, ainda, que o grupo na faixa 18 aos 30 anos reportou maiores percentuais de sintomas de ansiedade em toda a amostra (51\%), ainda que respondesse pela menor probabilidade de acompanhamento do noticiário.

Outras pesquisas internacionais indicam que a relação entre altas taxas de exposição a notícias e sentimentos de ansiedade se repetem mesmo quando não se trata de noticiário sobre eventos traumáticos. Caporino et al (2020) investigaram como as notícias sobre temas políticos durante a eleição presidencial em 2016 afetaram psicologicamente um grupo de crianças e jovens dos 6 aos 17 anos, residentes nos Estados Unidos, a partir de entrevistas com 374 responsáveis. O estudo apontou que mais de $50 \%$ deles consideraram que pelo menos uma das questões políticas cobertas pela mídia despertou sentimentos de preocupação entre seus filhos, sendo o meio ambiente e a violência os temas mais comuns.

A pesquisa também identificou que jovens com níveis clínicos de ansiedade apresentaram sintomas mais severos do que os que tinham ansiedade mínima ou subliminar. No entanto, os autores apontam outra característica importante para compreender a afetação juvenil pelas notícias: a empatia e a intolerância à incerteza. Conforme expressaram no seu artigo, "no clima político atual, a incerteza sobre o futuro pode ser exacerbada por mudanças frequentes de políticos eleitos, deixando os jovens com dificuldade de tolerar a incerteza e particularmente vulneráveis a preocupações" (idem. p.2).

\section{Letramento como antídoto}

Uma das alternativas para mitigar os efeitos da mídia sobre a saúde mental da população é a intervenção no campo do letramento midiático e informacional. Em editorial publicado em agosto de 2020, a revista The Lancet alertou para o fato de que teorias da conspiração e desinformação proliferam em tempos de incerteza e medo (The Truth is out there, somewhere 2020).

Em pesquisa com jovens estudantes de Ensino Médio, em 2018 (Felix 2019), observamos que a dificuldade em identificar fontes confiáveis de informação no cenário pré-eleitoral produzia medo e ansiedade entre o público observado. À medida que se sentiam mais aptos para avaliar e interpretar criticamente a produção de notícias, os integrantes da pesquisa, conduzida através de uma observação participante, se mostravam mais seguros em relação aos conteúdos e às fontes, e menos suscetíveis à afetação.

Com os novos desafios colocados pelo cenário de desinformação, a Unesco 
publicou um documento ressaltando a importância do letramento midiático e informacional para prevenir a manipulação de processos democráticos e empoderar os cidadãos. O manual Jornalismo, fake news e desinformação, publicado em Paris, em 2018, chegou ao Brasil em 2019, após as eleições presidenciais, igualmente pautadas pelo fenômeno da desordem informativa. Embora voltado ao ensino do Jornalismo, o documento reconhece que ações da mídia devem somar-se a programas mais amplos de Alfabetização informacional e midiática dos públicos (Ireton 2019).

No capítulo dedicado especificamente ao combate à desinformação e à informação incorreta por meio da alfabetização midiática e informacional, o documento avança na compreensão dos fatores que intervém na produção, circulação e consumo de sentidos e de como a AMI pode capacitar os sujeitos a compreender estes processos:

(...) a AMI também precisa prestar atenção para conscientizar as pessoas sobre como elas respondem a conteúdos de notícias, e suas predisposições para darem credibilidade ou não à informação, independente de parecerem notícias ou não. Portanto, a AMI deve, em sua essência, dar aos indivíduos uma visão de sua própria identidade - quem são e quem estão se tornando, e como isso afeta seu engajamento com notícias e outros tipos de comunicação (AbuFadil 2019, p. 76).

A habilidade para analisar as mensagens que circulam nas mídias exige, portanto, a capacidade de avaliar como somos afetados por elas e de que maneira nosso comportamento é guiado não apenas pela confiança, mas também pela necessidade de reiterar os próprios pontos de vista ou encontrar consolo para os desafios cotidianos. Neste sentido, o letramento midiático e informacional pode ajudar a reduzir a recirculação de mensagens produzidas intencionalmente com o objetivo de produzir tumulto social. Da mesma forma, pode contribuir para uma leitura crítica da mídia e para uma cidadania ativa, reduzindo as incertezas, o medo e a ansiedade.

No caso da situação pandêmica, no entanto, como aponta o estudo de Nekliudov et al (op. cit.), só o letramento midiático e informacional não consegue, isoladamente, reduzir o medo e a insegurança. A confiança na capacidade de agentes governamentais para agir em meio à crise é fundamental para mitigar incertezas e produzir um ambiente propício ao bem-estar físico e emocional.

\section{Juventude e mídia em tempos de pandemia}

Para além de questões geopolíticas e de gestão de saúde, interpretamos as respostas dos questionários de nossa pesquisa à luz dos fatores geracionais, ponderando o que a suspensão das atividades sociais, educacionais e laborativas regulares significa, em especial, para esses segmentos populacionais. Segundo os agrupamentos etários predeterminados para os respondentes, quase $2 / 3$ tinham até 24 anos. $O$ adiamento ou suspensão da experiência em marcos sociais típicos, como ingresso na universidade e primeiro emprego, também contribuem para o sentimento de perda e produção de angústia entre esses jovens. 
Entre os que tinham de 15 a 18 anos (233), 73\% ainda não haviam completado o ensino médio e 3\% tinham graduação incompleta; enquanto entre os de 19 a 24 anos (230), 1,5\% ainda não tinham completado o ensino médio e 62\% tinham graduação incompleta. Em relação ao fator trabalho e renda, dentre o grupo de 15 a 18 anos, 92\% declararam não trabalhar e, dos que alegavam trabalhar, a importância de sua contribuição para a renda da casa era média ou alta para quase 40\%. Já no grupo imediatamente subsequente, entre 19 e 24 anos, pouco mais da metade dizia não trabalhar e, para os $48 \%$ que mencionaram trabalhar, sua contribuição para a renda do lar era média ou alta para $60 \%$.

Dessa forma, não podemos ignorar que longos meses de interrupção total ou parcial das atividades rotineiras afetaram de modo importante o imaginário social e a percepção de futuro das camadas mais jovens da população, contribuindo para a degradação de fatores psicológicos.

Outra questão importante a se considerar na análise é a temporalidade decorrida entre o início da pandemia, e seus desdobramentos, e a liberação do questionário para coleta de respostas. A pesquisa foi disponibilizada em 24 de novembro de 2020, 259 dias após a Covid-19 ser declarada pandemia pela Organização Mundial da Saúde, o que ocorreu em 11 de março de 2020.

Assim, quase um ano após o primeiro lockdown coordenado, e ainda antes do início da segunda onda da doença no país, o tema continuava muito presente na mídia, no entanto, havia se tornado mais familiar. Portanto, mesmo que não menos negativa, a temática entrou nas rotinas, perdendo parte do apelo de ineditismo. Neste sentido, as questões propostas no questionário buscavam recuperar as percepções do evento ao longo do tempo, considerando todas as implicações advindas dessa exposição prolongada.

A partir desse contexto percebemos o que já era previsto: a grande maioria dos jovens participantes do estudo se sentia ainda mais pressionada pela situação quando ela era midiaticamente ratificada. Entretanto, também vimos um cenário menos esperado: quase $1 / 4$ dos respondentes não se sentiam mais tão abalados com a comunicação pandêmica em comparação com os meses anteriores.

Para melhor compreender esse comportamento, perguntamos se nossos e nossas respondentes consideravam que o noticiário sobre a Covid-19 prejudicava sua saúde emocional, ao que $65,5 \%$ indicavam que sim; $21,4 \%$ acreditavam que já havia prejudicado, mas não mais; e 11,9\% diziam que não. Quando indagados mais especificamente sobre que emoções eram incitadas pelo consumo noticioso diretamente vinculado à pandemia, com direito a múltiplas respostas, a maioria citou sentimentos negativos, como ansiedade ( $71,2 \%)$, angústia (64\%), medo (54\%) e tristeza $(51,2 \%)$.

Ao mesmo tempo, emoções que poderiam indicar certa expectativa de rápida 
e eficiente superação do problema ocupavam espaços significativamente mais singelos nas mentes desse público, como esperança (31,9\%), solidariedade (26\%) e otimismo (12,5\%).

Apesar de um pequeno percentual ter declarado que as notícias sobre o tema não eram tão relevantes para seu equilíbrio emocional (3,5\% declaram-se pouquíssimo afetados e $6,2 \%$ pouco afetados), os números dos que sentem o peso da temática, ressaltada pelas informações jornalísticas, são importantes. Se somadas as avaliações de afetações médias, altas e muito altas, temos $90,4 \%$ dos jovens da amostra abalados de algum modo pelas circunstâncias atuais e sua reafirmação constante nas diversas mídias. Cerca de $1 / 4$ do total expressavam, ainda, altíssima influência midiática no modo como vivem a experiência pandêmica.

É importante ressaltar que não estamos advogando que esse ou qualquer outro grupo social específico sofra mais ou menos na situação estudada, como se fosse possível desenhar uma régua para essa sensação de angústia. Apenas gostaríamos de destacar que os indivíduos que definimos como "jovens" vivem seus próprios dramas. Estes estão associados ao amplo medo de uma doença desconhecida, altamente contagiosa e letal, pois precisam suspender seus planos por tempo indeterminado e sem compreender muito bem que futuro virá e como poderão se adaptar a ele.

Nesse sentido, Caporino et al (2020) consideram a possibilidade de os jovens estarem mais suscetíveis a sintomas de ansiedade, reforçada por uma nova exposição, agora midiática, ao evento traumático. Como consequência, tenderiam a buscar mais informações sobre o assunto do que aqueles que pareciam dar menor importância ao tema.

Vale explicar, ainda, que pensamos na juventude como um conceito construído a partir de diversos parâmetros, dentre os quais a idade é apenas mais um componente. De tal maneira, os "modos de ser jovem" se vinculam à contextualização histórica, a relações geracionais, de gênero, etnia, classe social, moradia, família e pertencimento religioso, afinal não é a todos os indivíduos da categoria estatística juvenil que se oferece a condição histórico-cultural de juventude (Margulis; Urresti 1996 apud Baiense et al. 2016). Tais questões, e suas imbricações com os modos de afetação pela mídia, serão tratadas de forma qualitativa numa segunda etapa da pesquisa.

Não é surpreendente, portanto, que a esmagadora maioria (77\%) de nossos respondentes admitissem fugir do noticiário ou de redes sociais, eventual ou frequentemente, para evitar as informações sobre a pandemia: apenas 22,9\% da amostra declararam jamais mudar de noticiário ou rede social porque não queriam estar em contato com o tema pandemia. Esse aspecto mostra como as audiências juvenis lidam com a relação consumo-ansiedade exacerbada na cobertura de eventos traumáticos, na dicotomia consumir versus não consumir.

Por fim, pudemos colher alguns comentários que nos dão pistas a respeito do 
incômodo produzido pela pandemia e sua relação com o noticiário. Ainda que muitos apontassem o impacto do noticiário na produção de sentimentos negativos, notamos que a participação e a contribuição de outros atores sociais na situação de saúde global atual ganha destaque nessas falas. Isso nos parece claro quando dois respondentes expuseram que, apesar do desconforto emocional produzido pelo noticiário, preferiam se manter informados sobre a pandemia. Quatro deles também indicaram que sua principal fonte de incômodo não era o noticiário em si, mas as respostas pouco responsáveis de amplos grupos da população à situação vivida. Da mesma forma, a inexistência ou ineficiência de ações governamentais para fazer frente à conjuntura pandêmica é apontada como fonte de medo e ansiedade.

\section{CONCLUSÕES}

Ao longo do último ano, assistimos a uma espetacularização da vida cotidiana na cobertura da pandemia de Covid-19. O uso de imagens de espaços até então restritos, como centros de terapia intensiva e cemitérios, produziu um choque semelhante ao vivido no trauma (Kilomba, op. cit), pondo em risco a saúde mental das audiências. Tais práticas jornalísticas têm incitado discussões éticas, estimulado a publicação de guias de boas práticas (objETHOS 2020) e a organização de eventos voltados à formação de jornalistas em comunicação e saúde.

Para além da discussão ética da profissão, ainda notamos que o constante resgate de histórias pessoais de mensagens positivas ou negativas em relação à doença intensifica a sensação de sofrimento e angústia do espectador/leitor/ouvinte; produzindo uma segunda exposição a experiências traumáticas de cunho mais pessoal, vividas com familiares e amigos.

Podemos atestar que, em menor ou maior grau, esses indivíduos têm a saúde mental afetada pelo noticiário e há impactos em sua percepção de mundo. Contudo, nos parece que, apesar de lidarem de formas muito diferentes com as notícias sobre o evento traumático, identificam a importância do jornalismo de credibilidade para que haja a melhor compreensão dos fatos.

Os sentimentos juvenis transbordam e se misturam ao entrarem em contato com o noticiário. Em nossa pesquisa, eles aparecem através da raiva, ansiedade, tristeza, angústia, incredulidade e medo. O significado político desses afetos ainda não está claro, e será objeto de novas investigações. Mas acreditamos que eles vão impactar as respostas geracionais para a grave crise que enfrentamos, cujas consequências ainda não podemos dimensionar, mas que ajudarão a moldar nosso futuro. 


\section{AGRADECIMENTOS}

Agradecemos o apoio da Faperj ao projeto Juventude e Suicídio: percursos midiáticos e suas interfaces com a Educação, do qual o grupo Mídia, redes e jovens faz parte.

\section{FINANCIAMENTO}

Esta pesquisa conta com recursos do edital de Apoio a grupos emergentes de pesquisa do Estado do Rio de Janeiro da Fundação Carlos Chagas Filho de Apoio à Pesquisa do Estado do Rio de Janeiro (Faperj), processo número E26/010.002154/2019.

\section{REFERÊNCIAS}

ABU-FADIL, Magda, 2019. Combate à desinformação e à informação Incorreta por meio da alfabetização Midiática e informacional (AMI). Em: IRETON, Chrerilyn, POSETIT, Julie. Jornalismo, fake news e desinformação. Manual para Educação e Treinamento em Jornalismo. Série Unesco sobre Educação em Jornalismo. Brasília: UNESCO.

BAIENSE, Carla et al., 2016. Confiança e consumo da mídia impressa entre jovens: apontamentos a partir da Pesquisa brasileira de mídia. Revista Mediação, Belo Horizonte, v. 18, n, 22.

BARCELOS, Janaina Dias, 2020. Entre o medo, a guerra e a esperança: a cobertura da pandemia do novo coronavírus pela Revista Veja. Revista Dispositiva, v. 9, n. 16, p. 168187.

BODAS, Moran et al., 2015. Anxiety-Inducing Media: The Effect of Constant News Broadcasting on the Well-Being of Israeli Television Viewers. Psychiatry, v. 78, n. 3, p. 265-276, DOI: 10.1080/00332747.2015.1069658.

Brasil, 2013. Estatuto da Juventude. Brasília, 2013.

Brasil atinge 300 mil mortos por Covid-19 um dia após recorde de mais de 3 mil vidas perdidas em 24 horas. G1, 24/03/2021.

https://g1.globo.com/bemestar/coronavirus/noticia/2021/03/24/brasil-atinge-300-milmortos-por-covid-19-um-dia-apos-recorde-de-mais-de-3-mil-vidas-perdidas-em-24horas.ghtml

CAJAZEIRA, Paulo Eduardo Silva Lins et al., 2020. A monotematização da cobertura jornalística da Covid 19 no Jornal Nacional e Jornal da Record. Revista Pauta Geral Estudos em Jornalismo, v.7.

CAPORINO, Nicole E., EXLEY, Shannon; LATZMAN, Robert, 2020. Youth anxiety about political news. Child Psychiatry \& Human Developtment. 
CASERO-RIPOLLÉS, Andreu, 2020. Impacto da Covid-19 nos sistemas de mídia: consequências comunicativas e democráticas do consumo de notícias durante $o$ surto. Comunicação e Educação. Ano XXV, n. 1.

Coronavírus Brasil. Disponível em https://covid.saude.gov.br/. Acesso em 30 de mar. 2021.

DUARTE, Michael de Quadros; SANTO, Manuela Almeida da Silva;LIMA, Carolina Palmeiro; GIORDANI, Jaqueline Portella. TRENTINI, Clarissa Marceli.Covid-19 e os impactos na saúde mental: uma amostra do Rio Grande do Sul. Ciência Saúde Coletiva, $\mathrm{n}^{\circ} 25$, Set 2020. Disponível em:

<https://www.scielo.br/j/csc/a/ghSHWNYkP6gqJm4LQVhkB7g/?lang=pt> Acesso em: 11 jun. 2021

DAYRREL, Juarez, 2007 A escola "faz" as juventudes? Reflexões em torno da socialização juvenil. Educ. Soc., Campinas, vol. 28, n. 100 - Especial, p. 1105-1128.

EDMUNDS, June; TURNER, Bryan S., 2005. Global generations: social change in the twentieth century. In: The British Journal of Sociology. V. 56, ed. 4.

EYSENBACH, Gunther, 2020. How to Fight an Infodemic: The Four Pillars of Infodemic Managemen. Em: Journal of medical internet reseach. V. 22. Ed. 6. p. 1-6.

FELIX, Carla Baiense, 2019. Juventude e midiatização: Usos e apropriações das mídias a partir do cotidiano escolar. Relatório de pesquisa.

FELIX, Carla Baiense, FERNANDES, Patrícia, 2018. Entre o protagonismo e a angústia: apontamentos sobre o cotidiano midiatizado da juventude urbana. XXVII Encontro Anual da Compós. Anais do XXVII COMPÓs: Belo Horizonte/MG.

FREITAS, Viviane Gonçalves, BAPTISTA, Érica Anita, 2020. 100 MIL MORTES: O saldo negativo da Colvid-19 nos telejornais brasileiros. Revista Dispositiva, v. 9, n. 16, p. 168187 .

Ireton, Cherilyn. \& Posetit, Julie, 2019. Jornalismo, fake news e desinformação. Manual para Educação e Treinamento em Jornalismo. Série Unesco sobre Educação em Jornalismo. Brasília: Unesco.

GARCIA, Rafael. $7 \%$ dos brasileiros afirmam que Terra é plana, mostra pesquisa. Folha de S. Paulo. 14 jul. 2019. Disponível em

<https://www1.folha.uol.com.br/ciencia/2019/07/7-dos-brasileiros-afirmam-que-terrae-plana-mostra-pesquisa.shtml>. Acesso em: 31 mar. 2021.

GHEBREYESUS, Tedros Adhanom. Munich Security Conference. Genebra: WHO, 2020. Disponível em: https://www.who.int/dg/speeches/detail/munich-security-conference. Acesso em: 29 mar. 2021.

HALBWACHS, Maurice, 2006. A memória coletiva. Tradução de Beatriz. Sidou. $2^{\mathrm{a}}$ ed. São Paulo: Centauro. 
Juventudes e Pandemia do Coronavírus, 2020. Conselho Nacional de Juventude (Conjuve), 2020.

KILOMBA, Grada, 2020 Memórias da plantação. Episódios de racismo cotidiano. Rio de Janeiro: Cobogó.

MAFFESOLI, Michael, 1998 Elogio da Razão Sensível - Textos Filosóficos. Petrópolis: Vozes, 1998.

MANNHEIM, Karl, 1952. The problem of generations. Em P. Kecskemeti (Ed.), Essays on the Sociology of Knowledge. London: Routledge and Kegan Paul.

MOREIRA, Matheus. Convenção em São Paulo reúne quem duvida de que a Terra seja redonda. Folha de S. Paulo. 11 nov. 2019. Disponível em <https://www1.folha.uol.com.br/ciencia/2019/11/convencao-em-sao-paulo-reunequem-duvida-de-que-a-terra-seja-redonda.shtmll>. Acesso em: 31 mar. 2021.

NEKLIUDOV, Nikita A. et al., 2020. Daniel. Excessive Media Consumption About COVID-19 is Associated With Increased State Anxiety: Outcomes of a Large Online Survey in Russia. J Med Internet Res, vol. 22, n. 9.

objETHOS, 2020. Guia de Cobertura Ética da Covid-19.

PAINEL Coronavírus. Ministério da Saúde. 10 jun. 2021. Disponível em <https://covid.saude.gov.br/>. Acesso em: 11 jun. 2021.

PANDEMIA muda rotina e traz estresse, medo e violência para jovens de periferia Problemas vão de queda na renda familiar e falta de internet para acompanhar aulas a agressões domésticas. Dom Total. 21 fev. 2021. Disponível em <https://domtotal.com/noticia/1496785/2021/02/pandemia-muda-rotina-e-trazestresse-medo-e-violencia-para-jovens-de-periferia/>. Acesso em: 11 jun. 2021.

PNAD 2019. IBGE.

POSETTI, Julie; BONTCHEVA, Kalina, 2020. Desinfodemia. Decifrando la desinformación sobre el COVID-19. Unesco. Disponível em:

<https://en.unesco.org/sites/default/files/disinfodemic_deciphering_covid19_disinfor mation_es.pdf> Acesso em: 31 mar. 2021.

REFLEXÕES sobre os efeitos da pandemia na educação brasileira. Rede Covida Ciência, Informação e Solidariedade. Disponível em covid19br.org. Acesso em 29 mar 2020.

The truth is out there, somewhere, 2020. The Lancet, vol. 396.

TRENTIN, Lidia Paula, 2020. Pandemia: a veiculação de notícias sobre a Covid-10 nos sites de emissoras de rádio da Região Celeiro, RS. Revista Dispositiva, v. 9, n. 16, p. 168187. 